\title{
Adverse events in patients initiated on dabigatran etexilate therapy in a pharmacist- managed anticoagulation clinic
}

\author{
Mark DONALDSON, Amber O. NORBECK.
Received (first version):
}

\begin{abstract}
*
Background: Vitamin $\mathrm{K}$ antagonists have been the treatment of choice in preventing thromboembolic events, but problems such as frequent dose adjustment and monitoring of coagulation status, including multiple drug and food interactions, make their use difficult. Dabigatran etexilate is a new oral direct thrombin inhibitor not requiring routine monitoring and since its approval in the United States, many clinicians have been interested in utilizing this new therapy.

Objective: This study documented adverse drug events (ADEs) recorded in patients started on dabigatran therapy, including those who were previously controlled on warfarin and those who were anticoagulant naïve.

Methods: In an outpatient pharmacist-managed anticoagulation clinic, a total of 221 patients were initiated on dabigatran therapy over an 18-month period. $43.0 \%$ of these patients were previously controlled on warfarin.

Results: 54 of the 221 patients (24.4\%) developed an ADE while on dabigatran. The average time to event was 48.4 days. Nine of the fifty-four patients experienced a major bleeding ADE; six patients developed a serious non-bleeding ADE. Five of these fifteen patients died; one death was directly related to dabigatran therapy. The remaining thirtynine of the fifty-four patients experienced a clinically relevant non-major ADE. Of the fifty-four patients who experienced an ADE, thirty were male. The average age was 73.8 years and the average weight was $92.8 \mathrm{~kg}$. Fifty-four percent of those who experienced an ADE were previously anticoagulant naïve.

Conclusions: While many clinicians have been interested in utilizing the new direct thrombin inhibitor dabigatran etexilate, this new therapy is not without risks. This study documented adverse drug events in $24.4 \%$ of patients who were initiated on dabigatran etexilate therapy over an eighteen month period. ADEs were more common in patients who were anticoagulant naïve prior to dabigatran etexilate therapy and not those who were previously controlled on warfarin therapy.
\end{abstract}

\footnotetext{
"Mark DONALDSON. BSP, Pharm.D., FASHP, FACHE. Director of Pharmacy Services, Kalispell Regional Healthcare; \& Clinical Professor, School of Pharmacy, University of Montana. Missoula, MT (United States). Amber Olivia NORBECK, Pharm.D. Clinical Pharmacy Anticoagulation Specialist. Kalispell Regional Healthcare. Kalispell, MT (United States).
}

Keywords: Antithrombins; Benzimidazoles; Warfarin; Drug Toxicity; United States

\author{
EVENTOS ADVERSOS EN PACIENTES QUE \\ INICIAN TRATAMIENTO COM \\ ETEXILATO DE DABIGATRAN EN UNA \\ CLÍNICA FARMACÉUTICA DE \\ COAGULACIÓN
}

\section{RESUMEN}

Antecedentes: Los antagonistas de la vitamina $\mathrm{K}$ han sido el tratamiento de elección en la prevención de los eventos tromboembólicos, pero algunos problemas tales como los frecuentes ajustes de dosis y la necesidad de monitorización, incluyendo las múltiples interacciones medicamentosas, hacen que su uso sea difícil. El etexilato de dabigatran es un nuevo inhibidor oral directo de la trombina que no requiere la rutina de la monitorización y desde s autorización en los Estados Unidos muchos clínicos han estado interesados en utilizar esta nueva terapia.

Objetivo: Este estudio documenta los eventos adversos (ADE) registrados en pacientes que iniciaron tratamiento con dabigatran, incluyendo los que estaban previamente a tratamiento con warfarina y los que eran pacientes naive en anticoagulación.

Métodos: En una consulta farmacéutica de anticoagulación, un total de 221 pacientes iniciaron tratamiento con dabigatran en un periodo de 18 meses. El 43,0\% de estos pacientes estaban previamente estables con warfarina.

Resultados: 54 de los 221 pacientes (24,4\%) desarrolló un ADE con el dabigatran. El tiempo medio hasta el evento fue de 48,4 das. Nueve de los 54 pacientes sufrió un ADE hemorrágico grave; seis pacientes desarrollaron ADE graves no hemorrágicos. Cinco de esos 15 pacientes murieron: una muerte fue directamente asociada al tratamiento con dabigatran. Los restantes 39 (de los 54 pacientes) sufrió algún ADE no grave pero clínicamente relevante. De los 54 pacientes que sufrieron un ADE, 30 eran hombres. La edad media fue de 73,8 años y el peso medio de $92,8 \mathrm{Kg}$. El $54 \%$ de los que sufrieron un $\mathrm{ADE}$ eran naive a la anticoagulación.

Conclusión: Mientras que muchos clínicos se han interesado por el nuevo inhibidor directo de la trombina, el etixilato de dabigatran, este tratamiento ni está exento de riesgos. Este estudio documentó los eventos adversos en el $24,4 \%$ de los pacientes que iniciaron dabigatran en un periodo de 18 meses. Los ADE fueron más comunes en 
pacientes naive a la anticoagulación que en los que habían sido previamente tratados con warfarina.

Palabras clave: Antithrombinas; Benzimidazoles; Warfarina; Toxicidad de Medicamentos; Estados Unidos

\section{INTRODUCTION}

Kalispell Regional Medical Center in Northwest Montana is a 155-bed acute care, community, nonteaching, not-for-profit hospital. As the flagship hospital for the parent corporation, Kalispell Regional Healthcare, this campus is host to a number of medical specialties and clinics. In 2008, the inpatient hospital pharmacy department was asked to take over the management of the anticoagulation program at the organization's largest cardiology clinic. There is a growing body of evidence in support of pharmacist-run clinics which have been shown to reduce costs, major bleeding events, hospitalizations, emergency visits, and thromboembolism. ${ }^{1-8}$ Through the establishment of a collaborative practice agreement approved by the State Pharmacy Board, the new pharmacistmanaged anticoagulation clinic began operation in October 2008.

The clinic operates five days a week with an average daily census of thirty patients. While scheduling is arranged by the cardiology clinic staff to coincide with the patient's physician visit, the pharmacist manages the appointment; interviews and counsels the patient; performs finger-stick blood droplet testing to determine the patient's INR on a point-of-care device; makes treatment decisions based on these results and; completes all appropriate documentation. ${ }^{9}$ While warfarin has been the treatment of choice in preventing thromboembolic events, problems such as the need for frequent dose adjustment and monitoring of coagulation status, including multiple drug and food interactions, make their use difficult for both clinician and patient. Dabigatran etexilate is a new oral direct thrombin inhibitor, given in fixed doses not requiring routine coagulation monitoring like traditional warfarin therapy. With the approval of this new, novel oral anticoagulant in the United States in October of 2010, many prescribers were interested in starting patients on dabigatran etexilate therapy instead of warfarin. However, with this seemingly simplistic new agent - fixed dosing, lack of monitoring, and less concern for drug interactions the majority of patients had typically been started on dabigatran etexilate by the prescriber without pharmacist involvement. Over time, concerns from our physicians led to an audit of adverse drug events (ADEs) that was completed by the pharmacist-managed anticoagulation clinic.

This study documented adverse drug events recorded in patients started on dabigatran etexilate therapy, including those who were previously controlled on warfarin and those who were anticoagulant naïve. Since patient safety is always our number one concern, our main impetus for undertaking this study was a recent trend in our clinic of patients either being started on, or changed to, dabigatran etexilate therapy, and physician concerns in regards to bleeding events. Since the completion of this study, our clinicians have gained greater clinical confidence to safely start, manage and transition patients among these different treatment options.

\section{METHODS}

This study, conducted between October 15, 2010 and April 1, 2012, began as a retrospective chart review of patients on dabigatran etexilate therapy and continues as a prospective, intention-to-treat analysis, completed by a pharmacist-managed anticoagulation clinic in a rural setting. The Institutional Review Board at Kalispell Regional Medical Center determined that this retrospective chart review was exempt from requiring formal approval. To evaluate adverse drug events recorded in patients started on dabigatran etexilate therapy, a convenience sample of 221 patients were sequentially selected. Forty-three percent of these patients $(n=95)$ were previously on warfarin therapy while fifty-seven percent of these patients $(n=126)$ were anticoagulant naïve. For those patients already on warfarin, dabigatran etexilate was not introduced until the INR was less than two.

While reasons for the prescription change were not given for all patients, many patients reported their preference to be on a medication that no longer required a blood test to monitor efficacy and toxicity. Some patients commented that they were looking forward to being treated with a new medication that no longer required dietary restrictions. Physicians initiated the change in therapy regardless of the patients' time in the therapeutic range. That is, whether a patient had been stable on warfarin for a few months or a few years, the decision was made to change to dabigatran etexilate therapy.

To determine if the dose of dabigatran etexilate was appropriate as selected by the prescriber, the patients' creatinine clearance $(\mathrm{CrCl})$ was calculated by the Cockcroft-Gault equation; both actual body weight and ideal body weight were used to calculate the creatinine clearance to evaluate whether there was an appreciable difference that would change recommendations for the dose - especially in patients who were significantly overweight as using actual body weight can overestimate creatinine clearance in this population. ${ }^{10}$

We utilized the same definitions for bleeding ADE's as previously described in the literature to ensure our results would be easily translatable and comparable to earlier studies. ${ }^{11}$ For non-bleeding ADE's we used the FDA's definition of a serious ADE (Table 1). ${ }^{12}$

\section{RESULTS}

The results of our study are represented in an Online Appendix. Fifty-four of the 221 patients (24.4\%) developed an ADE while on dabigatran etexilate. The average time to event after the start of dabigatran etexilate treatment was 48.4 days 


\begin{tabular}{|c|c|}
\hline Adverse Drug Events (ADEs) & Definitions \\
\hline Major Bleeding & $\begin{array}{l}\text { Defined as overt bleeding and decrease of } \geq 20 \mathrm{~g} / \mathrm{L} \text { in hemoglobin concentration; } \\
\text { transfusion of } \geq 2 \text { units packed cells or whole blood; fatal, retroperitoneal, } \\
\text { intracranial, intraocular, or intraspinal bleeding; or bleeding warranting treatment } \\
\text { cessation or reoperation. }\end{array}$ \\
\hline Clinically-Relevant Nonmajor Bleeding & $\begin{array}{l}\text { Defined as spontaneous skin hematoma of } \geq 25 \mathrm{~cm}^{2} \text {, wound hematoma of } \geq 100 \mathrm{~cm}^{2} \text {, } \\
\text { epistaxis for more than five minutes, macroscopic hematuria, spontaneous rectal } \\
\text { bleeding, gingival bleeding for more than five minutes, or other bleeding events } \\
\text { judged clinically significant. }\end{array}$ \\
\hline Minor Bleeding & $\begin{array}{l}\text { Defined as bleeding events not fulfilling the criteria of major or clinically relevant } \\
\text { bleeding events. }\end{array}$ \\
\hline Adverse Drug Events (ADEs) & Definition \\
\hline Serious Adverse Event & $\begin{array}{l}\text { Any undesirable experience associated with the use of a medical product in a } \\
\text { patient. The event is serious when the outcome is death, life-threatening; results in } \\
\text { hospitalization (initial or prolonged), disability or permanent damage, or requires an } \\
\text { intervention to prevent permanent impairment. }\end{array}$ \\
\hline
\end{tabular}

(range 1-344). Nine out of the 54 patients (16.7\%) experienced a major bleeding ADE while six out of the 54 patients $(11.1 \%)$ experienced a serious nonbleeding ADE. Five of these fifteen patients died; one death was directly related to dabigatran etexilate therapy. The remaining thirty-nine patients $(72.2 \%)$ experienced a clinically relevant non-major ADE: $27.8 \%$ of which were related to bleeding $(n=15)$, while $44.4 \%$ were non-bleeding ADE's $(n=24)$. Thirty of the fifty-four patients were male. The average age of the patients was 73.8 years (range 36-89) and the average patient weight was $92.8 \mathrm{~kg}$ (range $46.8-159.1 \mathrm{~kg}$ ). Fifty-four percent of those who experienced an ADE were previously anticoagulant naïve.

Of the 54 patients who developed an ADE while on dabigatran etexilate, the anticoagulant was discontinued in five patients without beginning an alternate therapy (patients \#9, \#13, \#17, \#20 and \#40); one whom had a thrombotic cerebral vascular accident (CVA) several months later (patient \#9). One patient who did not tolerate dabigatran etexilate, self-discontinued the medication and had a thrombotic CVA six days after stopping anticoagulant therapy (patient \#11). Four others died of unrelated causes (patients \#30, \#31, \#45 and \#51). The remaining surviving 44 patients who developed an ADE while on dabigatran etexilate were transitioned to an alternate oral anticoagulant or aspirin. In the case of the 31 patients who were previously controlled on warfarin therapy, and who developed an ADE while on dabigatran etexilate, they all returned to warfarin therapy.

Only one patient remained on the medication despite the ADE which occurred, but the dose was decreased to $75 \mathrm{mg}$ twice daily having had only 15 days of dabigatran etexilate treatment (patient \#51). Unfortunately, this 82 year-old male died forty-two days later after a myocardial infarction.

A total of five patients died, four of which while on dabigatran etexilate therapy. Two of these patients died from a myocardial infarction (patients \#31 and \#51); one died from unknown causes (patient \#30); and one patient with a history of chronic alcoholism and esophageal varices succumbed to an upper gastrointestinal bleed which was determined to be caused by his dabigatran etexilate treatment (patient \#45).

\section{DISCUSSION}

Meticulous monitoring of patients on warfarin therapy is important due to the very narrow therapeutic window; subtherapeutic anticoagulation can increase the risk of clot formation leading to increased chance of stroke or venous thromboembolism, while supratherapeutic anticoagulation increases the risk for bleeding. Additional problems such as the need for frequent dose adjustments and multiple drug and food interactions, make the use of vitamin $\mathrm{K}$ antagonists difficult for both clinician and patient. Dabigatran etexilate is a new oral direct thrombin inhibitor, given in fixed doses, not requiring routine coagulation monitoring like traditional warfarin therapy.

Since its approval in the United States, many clinicians have been interested in utilizing this new therapy. The number of patients being treated with dabigatran etexilate continues to rise, however, there is a growing body of evidence being reported in the postmarketing surveillance literature to suggest that the potential risks of this drug are not generally appreciated. ${ }^{13-17}$ From the pivotal Randomized Evaluation of Long-Term Anticoagulation Therapy (RE-LY) study, bleeding is an expected complication with dabigatran etexilate (the incidence of major bleeding depending on the dose administered was $2.7-3.1 \%)^{18}$ In the dabigatran etexilate versus enoxaparin for prevention of venous thromboembolism after total hip replacement (RE-NOVATE) trial, the incidence of major bleeding was $1.3-2.0 \%,{ }^{19}$ and in the dabigatran etexilate versus enoxaparin for the prevention of venous thromboembolism after total knee replacement (RE-MODEL) trial, the incidence of major bleeding was $1.3-1.5 \%{ }^{20}$ In our study almost all of the patients received the standard $150 \mathrm{mg}$ twice a day dose and the overall incidence of major bleeding was $4.1 \%(n=9)$. The incidence of serious non-bleeding ADE's was $2.7 \%(n=6)$.

Bleeding with dabigatran etexilate can be even more pronounced in the elderly, and can be 
compounded by poor renal function and low body weight. ${ }^{18,21}$ In RE-LY, the mean age and weight of patients were 71 years and $83 \mathrm{~kg}$, respectively, with a mean creatinine clearance of $68 \mathrm{~mL} /$ minute as calculated by the Cockcroft-Gault equation utilizing the patients' actual body weight. ${ }^{10}$ Less than one third of these patients were over 80 years of age or weighed less than $63 \mathrm{~kg}$, and less than $20 \%$ had a creatinine clearance of less than $50 \mathrm{~mL} /$ minute. $^{18,22}$ By contrast, the mean age and weight of all 221 patients in our study were 71.2 years and $93.6 \mathrm{~kg}$, respectively, with a mean creatinine clearance of $78.2 \mathrm{~mL} /$ minute based on actual body weight (56.5 $\mathrm{mL} /$ minute based on ideal body weight).

This can be compared to the mean age and weight of our sub-population of 54 patients who developed an ADE while on dabigatran etexilate, which were 73.8 years and $92.8 \mathrm{~kg}$, respectively, with a mean creatinine clearance of $70.6 \mathrm{~mL} /$ minute based on actual body weight $(50.9 \mathrm{~mL} /$ minute based on ideal body weight). One third of these patients $(n=16)$ who experienced an ADE were 80 years or older, or weighed less than $63 \mathrm{~kg}$. Nearly $28 \%$ of these patients had a creatinine clearance of less than 50 $\mathrm{mL} /$ minute based on actual body weight. This fraction increases to $48 \%$ if the creatinine clearance is calculated based on ideal body weight.

Dabigatran etexilate is eliminated primarily through the renal system so the appropriate dosing is dependent on the patients' renal function which is calculated by the Cockcroft-Gault equation utilizing the patients' actual body weight. ${ }^{10}$ According to the manufacturer's prescribing information, patients with a $\mathrm{CrCl}$ greater than $30 \mathrm{~mL} /$ minute should receive $150 \mathrm{mg}$ orally, twice daily, while patients with a $\mathrm{CrCl}$ between $15-30 \mathrm{~mL} /$ minute should receive $75 \mathrm{mg}$ orally, twice daily. ${ }^{23}$ This medication is not recommended for patients with a $\mathrm{CrCl}$ less than 15 $\mathrm{mL} /$ minute. The mean creatinine clearance for all patients who developed an ADE while on dabigatran etexilate was $70.6 \mathrm{~mL} /$ minute (range 18.8-124.7 $\mathrm{mL} /$ minute). Two of our patients (patients \#15 and \#26) should have had dosage reductions according to the manufacturers' prescribing information; two other patients experiencing ADE's had borderline creatinine clearances of $30-35 \mathrm{~mL} /$ minute (patients \#20 and $\# 40$ ). An additional four patients in total would have required a dosage decrease if their ideal body weight had been used to calculate their creatinine clearance rather than their actual body weight (patients \#20, \#25, \#30 and \#40).

This again highlights a potential methodology flaw and medication safety issue when dosing guidelines are based on studies that calculate renal function using actual body weight rather than ideal body weight; creatinine clearance can be significantly overestimated in an overweight population. Of the 54 patients experiencing an ADE, five patients $(9.3 \%)$, should have been on a lower dose based on renal function and/or concurrent drug interactions. An additional five patients may have benefited from a dosage decrease if ideal body weight was used to calculate the creatinine clearance.
The U.S. prescribing information for dabigatran etexilate at the time of this study was vague in regard to dosing changes based on potential drug interactions. ${ }^{23}$ The product monograph recommends, "avoiding concurrent use of any $\mathrm{P}$ glycoprotein inhibitor if the patient's creatinine clearance is less than $30 \mathrm{~mL} /$ minute," but does not recommend any other explicit dose reductions specifically for verapamil and amiodarone. ${ }^{23}$ According to the dabigatran etexilate Canadian product monograph, "for prevention of venous thromboembolism following hip or knee replacement, the dabigatran etexilate dose should be reduced for patients on verapamil or amiodarone"; ${ }^{24}$ however, no specific dose reduction is recommended for prevention of stroke and systemic embolism in patients with atrial fibrillation. The Canadian monograph also recommends administration of dabigatran etexilate 2 hours prior to oral verapamil - something that is noticeably absent from the U.S. prescribing information. Of our 54 patients who experienced an ADE, fourteen $(25.9 \%)$ were on an interacting medication. According to the Canadian monograph, five of these fourteen patients should have had a dosage decrease; and, dabigatran etexilate should have been avoided in two of these patients based on an interacting medication and concurrent renal function. ${ }^{23,24}$

Our study illustrates the difficulty in extrapolating trial data into clinical practice and emphasizes the ongoing need for postmarketing surveillance and adverse-event reporting to detect groups whose risk factors may not be apparent in a clinical-trial setting.

Harper et al, recorded similar experiences in their cohort of frail, elderly patients who were placed on dabigatran etexilate and identified four major factors that contributed to these ADEs: prescriber error, impaired renal function, patient age, and complications arising from the lack of a reversal agent. ${ }^{23}$ Prescriber errors contributed to the majority of their bleeding episodes (approximately $25 \%$ of their patients), including the failure to allow the international normalized ratio to fall below 2.0 before starting dabigatran etexilate and the use of the drug in patients with severe renal impairment. We were able to avoid this potential error, with the exception of one patient who had a home INR monitor, by having a dedicated pharmacistmanaged anticoagulation clinic that facilitated the transition between warfarin and dabigatran etexilate upon physician request. During this transition, our specialists were also able to help avoid prescribing errors by ensuring that the dose was appropriate for renal function and screening for potential drug interactions that may require a dosage adjustment. Unfortunately, we could not impact and reduce the potential bleeding risk for patients presenting with advanced age, or complications that could arise from the lack of a reversal agent. However, when only considering our cohort of 15 patients who experienced a major bleeding ADE or serious nonbleeding ADE while on dabigatran etexilate therapy, the average age was still similar, although a little older, to our overall group (76 years-old; range 5887 years old versus 73.8 years-old; range 36-89). 
The discontinuation rate was $21.7 \%$ in our study population - almost identical to that in RE-LY $(21 \%)$.

Our main impetus for undergoing this study was a recent trend in our clinic of patients either being started on, or changed to, dabigatran etexilate therapy, and physician concerns in regards to bleeding events. Since patient safety is always our number one concern, especially with the introduction of newly-approved therapies that may have limited postmarketing surveillance data, we decided to retrospectively audit all patients started on this new therapy, including those who were previously controlled on warfarin and those who were anticoagulant naïve. To ensure our results would be easily translatable and comparable to earlier studies, we utilized the same definitions for bleeding ADE's as previously described in the literature and we used the FDA's definition of serious ADEs for nonbleeding events (Table 1). ${ }^{11,12}$ To mitigate any potential selection bias we opted for a sequential convenience sample of 221 patients in order to meet statistical power.

One final observation which may have potentially profound clinical implications was that ADEs were most common in patients who were not previously controlled on warfarin therapy; so-called anticoagulant naïve patients. In our study, fortythree percent of our patients $(n=96)$ were previously stable on warfarin therapy while fifty-seven percent $(n=127)$ of these patients were anticoagulant naïve before starting on dabigatran etexilate. Of the 54 patients who experienced an ADE while on dabigatran etexilate therapy, only forty-six percent $(n=25)$ of those were previously controlled on warfarin therapy, and only seven of these twentyfive patients developed a major bleeding $\operatorname{ADE}(n=3)$ or serious nonbleeding ADE $(n=4)$. These observations have raised more questions than conclusions:

Is it possible that we are being less vigilant in our patient selection when beginning anticoagulant naïve patients on this new direct thrombin inhibitor? Since dabigatran etexilate treatment does not require the same meticulous monitoring as warfarin therapy with its very narrow therapeutic window, need for frequent dose adjustments and multiple drug and food interactions, are we neglecting to counsel patients about the true risks of this new medication? Should these patients be routinely monitored for complications of anticoagulant therapy and to ensure compliance? Should a pharmacist be more involved in helping to determine the dose, screening for potential drug interactions; and whether patient is an appropriate candidate for dabigatran etexilate therapy?

Our results are consistent with those of previous investigators who also observed that the potential risks of this new medication may not be generally appreciated.

\section{CONCLUSIONS}

While many clinicians have been interested in utilizing the new direct thrombin inhibitor dabigatran etexilate, this new therapy is not without risks. This study in a pharmacist-managed anticoagulation clinic documented adverse drug events (ADEs) recorded in fifty-four patients out of a total of 221 patients $(24.4 \%)$ who were initiated on dabigatran etexilate therapy over an eighteen month period. ADEs were most common in patients who were not previously controlled on warfarin therapy.

\section{ACKNOWLEDGEMENT}

The authors wish to thank Dr. Brad Roy, Dr. John Sullivan and Dr. Michael Dotter for their critical review of this manuscript.

\section{CONFLICT OF INTEREST}

All authors disclose no potential conflicts of interest

\section{References}

1. Guyatt GH, Akl EA, Crowther M, Gutterman DD, Schuünemann HJ; American College of Chest Physicians Antithrombotic Therapy and Prevention of Thrombosis Panel. Executive summary: Antithrombotic Therapy and Prevention of Thrombosis, 9th ed: American College of Chest Physicians Evidence-Based Clinical Practice Guidelines. Chest. 2012;141(2 Suppl):7S-47S. doi: 10.1378/chest.1412S3.

2. Ansell JE, Hughes R. Evolving models of warfarin management: anticoagulation clinics, patient self-monitoring, and patient self-management. Am Heart J. 1996;132(5):1095-1100.

3. Nutescu EA. The future of anticoagulation clinics. J Thromb Thrombolysis. 2003;16(1-2):61-63.

4. Witte K, Gurwich EL, Anzalone R, Campagna MA. Audit of an oral anticoagulant teaching program. Am J Hosp Pharm. 1980;37(1):89-91.

5. Finck KM, Doetkott $\mathrm{C}$, Miller DR. Clinical impact of interlaboratory variation in international normalized ratio determinations. Am J Health Syst Pharm. 2001;58(8):684-688.

6. Griffin BL, Burkiewicz JS, Peppers LR, Warholak TL. International Normalized Ratio values in group versus individual appointments in a pharmacist-managed anticoagulation clinic. Am J Health Syst Pharm. 2009;66(13):1218-1223. doi: 10.2146/ajhp080278.

7. Bungard TJ, Gardner L, Archer SL, Hamilton P, Ritchie B, Tymchak W, Tsuyuki RT. Evaluation of a pharmacistmanaged anticoagulation clinic: Improving patient care. Open Med. 2009 Feb 2;3(1):e16-e21.

8. Chiquette E, Amato MG, Bussey HI. Comparison of an anticoagulation clinic with usual medical care: anticoagulation control, patient outcomes, and health care costs. Arch Intern Med. 1998;158(15):1641-1647. 
9. Donaldson M, Sullivan J, Norbeck A. A comparison of international normalized ratio values attained by two point of care methodologies and laboratory-based venipuncture in a pharmacist-managed anticoagulation clinic. Am J Health Syst Pharm. 2010;67(19):1616-1622. doi: 10.2146/ajhp100096.

10. Cockcroft DW, Gault MH. Prediction of creatinine clearance from serum creatinine. Nephron. 1976;16(1):31-41.

11. Blommel ML, Blommel AL. Dabigatran etexilate: A novel oral direct thrombin inhibitor. Am J Health Syst Pharm. 2011;68(16):1506-1519. doi: 10.2146/ajhp100348.

12. What is a serious adverse event? The United States Food and Drug Administration. June 2011. URL: http://www.fda.gov/safety/medwatch/howtoreport/ucm053087.htm (Accessed July 27, 2012).

13. Harper $P$, Young L, Merriman E. Bleeding risk with dabigatran etexilate in the frail elderly. $\mathrm{N}$ Engl J Med. 2012;366(9):864-6. doi: 10.1056/NEJMc1112874.

14. Eikelboom JW, Wallentin L, Connolly SJ, Ezekowitz M, Healey JS, Oldgren J, Yang S, Alings M, Kaatz S, Hohnloser $\mathrm{SH}$, Diener HC, Franzosi MG, Huber K, Reilly P, Varrone J, Yusuf S. Risk of bleeding with 2 doses of dabigatran etexilate compared with warfarin in older and younger patients with atrial fibrillation: an analysis of the randomized evaluation of long-term anticoagulant therapy (RE-LY) trial. Circulation. 2011;123(21):2363-2372. doi: 10.1161/CIRCULATIONAHA.110.004747.

15. Whitehead H, Boyd JM, Blais DM, Hummel J. Drug-induced exanthem following dabigatran etexilate. Ann Pharmacother. 2011;45(10):e53. doi: 10.1345/aph.1Q317

16. Hori M, Connolly SJ, Ezekowitz MD, Reilly PA, Yusuf S, Wallentin L; RE-LY Investigators. Efficacy and safety of dabigatran etexilate vs. warfarin in patients with atrial fibrillation--sub-analysis in Japanese population in $R E-L Y$ trial. Circ J 2011; 75(4):800-805.

17. Redberg RF. Important data after drug approval: comment on "Dabigatran etexilate association with higher risk of acute coronary events". Arch Intern Med. 2012;172(5):404. doi: 10.1001/archinternmed.2011.2169.

18. Connolly SJ, Ezekowitz MD, Yusuf S, Eikelboom J, Oldgren J, Parekh A, Pogue J, Reilly PA, Themeles E, Varrone J, Wang S, Alings M, Xavier D, Zhu J, Diaz R, Lewis BS, Darius H, Diener HC, Joyner CD, Wallentin L; RE-LY Steering Committee and Investigators. Dabigatran etexilate versus warfarin in patients with atrial fibrillation. $\mathrm{N}$ Engl $\mathrm{J}$ Med. 2009;361(12):1139-1151. doi: 10.1056/NEJMoa0905561.

19. Eriksson BI, Dahl OE, Rosencher N, Kurth AA, van Dijk CN, Frostick SP, Prins MH, Hettiarachchi R, Hantel S, Schnee J, Büller HR; RE-NOVATE Study Group. Dabigatran etexilate versus enoxaparin for prevention of venous thromboembolism after total hip replacement: a randomised, double-blind, non-inferiority trial. Lancet. 2007;370(9591):949-956.

20. Eriksson BI, Dahl OE, Rosencher N, Kurth AA, van Dijk CN, Frostick SP, Kälebo P, Christiansen AV, Hantel S, Hettiarachchi R, Schnee J, Büller HR; RE-MODEL Study Group. Oral dabigatran etexilate vs. subcutaneous enoxaparin for the prevention of venous thromboembolism after total knee replacement: the RE-MODEL randomized trial. $J$ Thromb Haemost. 2007;5(11):2178-2185.

21. Poli D, Antonucci E, Testa S, Tosetto A, Ageno W, Palareti G; Italian Federation of Anticoagulation Clinics. Bleeding risk in very old patients on vitamin $\mathrm{K}$ antagonist treatment: results of a prospective collaborative study on elderly patients followed by Italian Centres for Anticoagulation. Circulation. 2011;124(7):824-829. doi: 10.1161/CIRCULATIONAHA.110.007864.

22. Boehringer Ingelheim. Advisory committee briefing document submitted to the Food and Drug Administration. August 2010. Accessed July 13, 2012.

(http://www.fda.gov/downloads/advisorycommittees/committeesmeetingmaterials/drugs/cardiovascularandrenaldrugsad visorycommittee/ucm226009.pdf).

23. Pradaxa (prescribing information). Ridgefield, CT: Boehringer Ingelheim Pharmaceuticals, Inc.; 2010.

24. Pradax (prescribing information). Burlington, ON: Boehringer Ingelheim Canada Ltd.; 2012. 